\title{
DAVID HUME, O COMEÇO E O FIM
}

\author{
Déborah Danowski* \\ deborahdanowski@gmail.com
}

RESUMO O presente artigo analisa o uso abundante por Hume de ficções que relatam o que significaria para nós a ausência de experiência - ou porque esta ainda não existiria, ou porque, por algum motivo, ela não existira mais. Sugerimos que essas ficções, além de seu objetivo mais imediato de prestar o devido reconhecimento à experiência e ao hábito como únicos fundamentos possiveis de nossas inferências de causa e efeito, revelam a tensão permanente de nossa existência entre duas forças de atração: uma força que nos puxa em direção à regularidade e uniformidade das leis da natureza e da natureza humana, afastando-nos da singularidade, da pura diferença entre percepções atômicas e da indiferença original da imaginação; e uma outra, que apenas entrevemos, mas que se mantém como uma ameaça constante por trás de todas as associações, inferências, crenças e mecanismos de paixões: o reino da pura singularidade, a recaída na indiferença, a ruína da natureza humana.

Palavras-chave David Hume, experiência, natureza humana, indiferença, singularidade

ABSTRACT This paper analises some of the abundant ficticious situations conceived by Hume throughout his works to represent the absence of experience characterizing either an initial state, where experience doesn't

* PUC-Rio/CNPq. Artigo recebido em 25/11/2011 e aprovado em 22/12/2011.

1 Uma primeira versão deste texto foi apresentada em 2007, no III Colóquio Hume, na Universidade Federal de Minas Gerais, Brasil. A presente versão foi apresentada no Coloquio Interdisciplinario La Filosofía de David Hume a 300 años de su nascimiento, de 20 a 22 de julho de 2011, em Montevidéu, Uruguai.

KRITERION, Belo Horizonte, nº 124, Dez./2011, p. 293-305. 
exist yet, or a state where it doesn't exist anymore. We suggest that these fictitious situations, besides their more immediate goal of calling our attention to the fact that experience and habit are the only possible grounds for our causal inferences, also reveal the permanent tension between two opposite forces of attraction, to which our existences are subject according to Hume: one main force, that pulls us in the direction of the regularity and uniformity of natural laws and human nature, leading us away from the singularity, the pure difference among atomic perceptions, and the original indifference of imagination; and another force, which we perceive only in a shadowy way, but which nevertheless is present to us as a constant threat underneath all our associations, inferences, beliefs, and passions: the reign of pure singularity, the descent back into indifference, the ruin of human nature.

Keywords David Hume, experience, human nature, indifference, singularity

\begin{abstract}
Sinto-me assustado e confuso com a solidão desesperadora em que me encontro dentro de minha filosofia; imagino-me como um monstro estranho e rude que, por incapaz de se misturar e se unir à sociedade, foi expulso de todo relacionamento com os outros homens e largado em total abandono e desconsolo. (Hume, Tratado da Natureza Humana, 1.4.7.2)
\end{abstract}

David Hume tinha uma certa predileção por um tipo de situação imaginária que uma vez chamei de ficções de estranhamento. ${ }^{2}$ São ficções que relatam o que significaria a ausência de experiência, ou porque esta ainda não existiria, ou porque, por algum motivo, ela não existira mais.

Lemos, por exemplo, em textos diversos: "Se uma pessoa adulta e de natureza igual à nossa fosse subitamente transportada para nosso mundo..."; 3 "Se um homem como Adão fosse criado com todo o vigor de seu entendimento, mas sem experiência..."; "Se um homem abstraísse de tudo que conhece ou

2 No capítulo 5 de minha tese de doutorado, Natureza acaso: a contingência na filosofia de David Hume. Danowski 1991.

3 A Treatise of Human Nature, 2.1.6.9; edição Norton \& Norton, p.192; minha tradução, p. 328. Daqui em diante: "THN" para A Treatise of Human Nature, "NN" para a edição Norton \& Norton, "DD" para a edição brasileira.

4 An Abstract of A Treatise of Human Nature (daqui em diante: Abstract), 11; NN: 410, DD: 688. 
viu..."; "Caso um estranho [ a stranger] caísse subitamente neste mundo..."; 6 "Se uma inteligência bastante limitada, que suporemos sem qualquer conhecimento do universo..."; "7 "Se uma geração de homens saísse de cena de uma só vez e uma outra a sucedesse, como é o caso com os bichos-da-seda e as borboletas, a nova raça...". ${ }^{8}$ Etc.

De um modo geral, e antes de mais nada, quase todas essas ficções visam a prestar o devido reconhecimento à experiência e ao hábito, como únicos fundamentos possíveis de nossas inferências de causa e efeito. Representando um suposto ponto zero da experiência, em que os objetos e o mundo apareceriam pela primeira vez a um observador, Hume por um lado nos mostra que no mundo real esse ponto zero não existe, que estamos sempre já meio caminho andado, sempre já "habituados", sempre já longe daquilo que, de outra forma, seria um reino de contingência ilimitada e irredutível, acompanhado ou de uma imaginação tresloucada ou da mais pura apatia, talvez as duas coisas ao mesmo tempo. Por outro lado, o caráter inusitado dessas mesmas ficções, a sensação de estranhamento que produzem em nós, parecem ter também o papel de nos lembrar que nem o hábito nem a regularidade da natureza, por mais fortes que sejam, são capazes de eliminar completamente a incerteza decorrente da falta de um fundamento racional para nossas inferências causais e para nossos juízos morais.

Comecemos pelo começo, a saber, pela ficção do primeiro homem, Adão. Para ilustrar sua afirmação de que a razão e a demonstração não têm qualquer papel nas inferências sobre questões de fato, e de que, sem a experiência, tudo o que podemos conceber é igualmente possível, Hume traz à cena a figura de um Adão que, criado já pronto como seu modelo do Antigo Testamento, com faculdades mentais perfeitamente maduras, estaria bizarramente contemplando duas bolas em movimento, no que parece ser um jogo de bilhar:

Se um homem como Adão fosse criado com todo o vigor de seu entendimento, mas sem experiência, nunca seria capaz de inferir um movimento na segunda bola partindo do movimento e do impacto da primeira. O que nos faz inferir o efeito não é algo que a razão vê na causa. Uma tal inferência, se fosse possível, constituiria uma demonstração, por estar fundada exclusivamente na comparação de ideias. A mente sempre pode conceber que qualquer efeito se segue de uma causa e, aliás, que qualquer acontecimento se segue de outro; tudo que concebemos é possível, ao

5 Dialogues concerning Natural Religion (daqui em diante: DNR), Il; edição Norman Kemp Smith (daqui em diante: KS), p.145; tradução de José Oscar de Almeida Marques (daqui em diante: AM), p.34. Neste artigo utilizo, entretanto, minha própria tradução.

6 DNR, X; KS: 196; AM: 133.

7 DNR, XI; KS: 203; AM: 146.

8 Essays Moral, Political and Literary (daqui em diante: Essays), "Of the original contract", p.476. 
menos em um sentido metafísico; mas, sempre que há uma demonstração, o contrário é impossível, e implica contradição (...).

Teria sido necessário, portanto, que Adão (se não fosse inspirado) tivesse tido experiência do efeito que se seguiu ao choque dessas duas bolas. ${ }^{9}$

É a experiência, e no sentido forte, ou seja, a experiência enquanto "princípio", ${ }^{10}$ a experiência como uma repetição constante capaz de gerar hábitos, é ela que direciona a imaginação, a qual, de outro modo, não teria por que concluir que nosso futuro será semelhante a nosso passado. Esse Adão humeano, um Adão "não inspirado" e por isso muito diferente do Adão bíblico, é justamente o retrato do que seríamos sem essa experiência, por mais perfeitas que fossem nossas faculdades mentais.

Hume repete o exemplo de Adão em pelo menos duas outras ocasiões, introduzindo aos poucos variações que o tornam cada vez mais próximo da figura bíblica. Entretanto, temos a impressão de que, quanto mais Adão vai ganhando em coerência, mais ele perde em seu poder de causar estranhamento. O primeiro Adão, do Abstract, era ainda muito semelhante a nós, a única diferença sendo justamente a ausência total de hábitos que pudessem nele gerar crenças e expectativas. Mas sua experiência inaugural era a experiência de qualquer cidadão britânico civilizado da época do próprio Hume. Poderia ter surgido ali mesmo, ao lado do filósofo e de seus companheiros, num dos clubes de sinuca que ele gostava tanto de frequentar.

$\mathrm{Na}$ Investigação sobre o Entendimento Humano, entretanto, Adão não aparece mais na cidade. Surge em meio à natureza, num momento e lugar indeterminados, e seu primeiro contato se dá diretamente com dois dos elementos primordiais: a água e o fogo.

Adão, ainda que supuséssemos que suas faculdades racionais fossem inteiramente perfeitas desde o início, não poderia ter inferido da fluidez e transparência da água que esta o sufocaria, nem da luminosidade e do calor do fogo que este poderia consumi-lo. ${ }^{11}$

A experiência dos dois elementos primordiais não parece causar a esse segundo Adão nenhum verdadeiro espanto ou sentimento mais forte. Seu caráter inteiramente inusitado apenas o impede de fazer inferências ou tirar

9 Abstract, NN: 410, DD 688.

10 THN, 1.4.7.3; NN: 172; DD: 297: "A experiência é um princípio que me instrui sobre as diversas conjunções de objetos no passado. $O$ hábito é um outro princípio, que me determina a esperar o mesmo para o futuro..."

11 An Enquiry concerning Human Understanding (daqui em diante EHU), IV.I.23; edição Nidditch/Selby-Bigge (daqui em diante N/SB) p.27; tradução de José Oscar de Almeida Marques (daqui em diante AM), p.56. 
conclusões acerca do que vê. Mesmo assim, o breve texto nos deixa suspeitar a presença de ao menos duas paixões calmas: uma certa curiosidade em relação à natureza daqueles objetos e uma atração em sua direção, provocadas respectivamente (estou especulando) pelo sentimento do belo frente à transparência da água e à luminosidade do fogo, e pela sensação agradável proporcionada, talvez, pelo calor deste último. O leitor imagina o que pode se seguir: a água pode sufocá-lo, o fogo pode consumi-lo, caso Adão se precipite na direção de um ou de outro. Pressentimos que esse primeiro homem, ao contrário do personagem bíblico, pode não sobreviver por muito tempo. Mas o fato é que somos nós que pressentimos o perigo. O próprio Adão não tem dele a menor consciência. Nenhuma paixão ou emoção mais violenta é mencionada, em nenhum momento.

Algo muito diferente se passa na terceira versão da ficção adâmica, que encontramos na História Natural da Religião. Ali o cenário é bem mais condizente com o momento bíblico da criação. Adão se ergue, e vê o paraíso:

Adão, erguendo-se de uma só vez no paraíso, e de plena posse de suas faculdades, como o representa Milton, naturalmente se espantaria com as gloriosas aparências da natureza, os céus, o ar, a terra, seus próprios órgãos e membros; e seria levado a perguntar de onde uma cena tão maravilhosa havia surgido. ${ }^{12}$

O espanto e a curiosidade, aqui, parecem decorrentes de um sentimento que diríamos próximo do sublime. ${ }^{13}$ Mas o contexto não é mais o mesmo do Tratado da Natureza Humana ou da Investigação sobre o Entendimento Humano. Hume está investigando a origem histórica das formas religiosas. Adão tem o mundo inteiro à sua frente, e todo o tempo do mundo. Não corre perigo, não tem necessidades nem sobressaltos, ainda não é, como nós, escravo das paixões. Por isso a questão que se põe a si mesmo é sobre a causa dessa cena tão maravilhosa que constitui a própria natureza. E a resposta não poderia ser outra, segundo nos diz o texto: a causa é o Deus único, infinito, racional e perfeito do monoteísmo.

Pouco aqui lembra a sensação de estranheza, de deslocamento, que, por simpatia talvez, sentimos pelo Adão do Tratado e também da Investigação do Entendimento. Ao mesmo tempo em que lhe empresta a beleza poética do Paradise Lost, de Milton, Hume reinsere a figura de Adão em seu mundo

12 The Natural History of Religion I, edição H.E. Root, p.24.

13 Esta análise das modulações do personagem de Adão no texto humeano foi em parte inspirada em Hache e Latour, 2009, e em sua proposta de atentar para a "sensibilidade moral" (mas não "moralista") de alguns textos escolhidos. 
próprio, levando-o definitivamente para longe de nós. Assim é que, daquele paraíso bíblico à nossa dura realidade, o contraste é brutal. Eu cito agora um pedaço mais extenso do trecho de onde retirei a citação anterior:

As causas dos objetos que nos são familiares nunca despertam nossa atenção ou curiosidade (...) Adão, erguendo-se de uma só vez no paraíso, e de plena posse de suas faculdades, como o representa Milton, naturalmente se espantaria com as gloriosas aparências da natureza, os céus, o ar, a terra, seus próprios órgãos e membros; e seria levado a perguntar de onde uma cena tão maravilhosa havia surgido. Mas um animal bárbaro e necessitado (como o homem na origem da sociedade), pressionado pela penúria e por paixões tão numerosas, não tem tempo para admirar a face regular da natureza, ou colocar questões sobre a causa desses objetos aos quais se acostumou gradativamente desde a infância (idem, minha tradução, meu grifo).

Nada em nossa própria origem, portanto, lembra a cena bíblica. $\mathrm{Na}$ verdade, é preciso lembrar que, apesar das cenas fictícias que estamos analisando, Hume não se interessa muito pela questão da gênese real primeira de nossos hábitos ou da sociedade. O que ele aqui chama de "origem da sociedade" são os estágios iniciais de um processo já em curso. Desde que nos entendemos por gente, somos pressionados de todos os lados por necessidades e paixões. O hábito está de tal modo entranhado em nossas vidas, que acreditamos que a determinação que sentimos em nossa mente é reflexo de uma determinação existente nas próprias coisas; pois é justamente ali onde esse princípio da natureza humana, o hábito, é mais forte que ele menos se faz notar. Na Investigação sobre o Entendimento, na seção seguinte àquela em que dera o exemplo de Adão defrontando-se pela primeira vez com a transparência da água e com a luminosidade do fogo, Hume resgata a cena do jogo de bilhar mencionada no Tratado, porém agora tendo nós mesmos como protagonistas: "Imaginamos que, se tivéssemos sido trazidos de súbito a este mundo, poderíamos ter inferido desde o início que uma bola de bilhar iria comunicar movimento a uma outra por impacto". ${ }^{14}$

Para mostrar que na verdade não poderíamos ter feito tal inferência, portanto, Hume precisava de Adão, mas o Adão de que precisava era mesmo aquele primeiro, do Tratado, um Adão surgindo dentro de nosso mundo mais cotidiano, e ao mesmo tempo absolutamente estranho a ele. Apenas essa estranheza seria capaz de nos fazer ver o quanto nós de fato devemos ao hábito e à experiência. 
Essa sensação de estranheza, entretanto, parece-me ter uma segunda função, igualmente importante, no texto humeano. É que a segurança que sentimos acerca da regularidade da natureza, a confiança de que a experiência futura não irá nos desapontar, de que, ao contrário, ela confirmará aquilo que nossos hábitos nos fazem esperar, esse sentimento na verdade é mais frágil do que parece. Isso porque, diz Hume, "se houver qualquer suspeita de que o curso da natureza pode vir a modificar-se, e de que o passado pode não ser uma regra para o futuro, toda a experiência se tornará inútil, e incapaz de dar origem a qualquer inferência ou conclusão". ${ }^{15}$

Ora, a possibilidade de despertar essa suspeita, há muito em nós adormecida sob a força do hábito, é isso que me parece ser também de alguma forma sugerido pelo uso abundante que Hume faz de ficções como aquela de Adão. Uma tal suspeita, a suspeita da intransponível instabilidade do mundo, nos lançaria, enquanto permanecêssemos sob sua influência, num estado semelhante (embora ampliado) àquele gerado por algumas situações bem particulares, tais como aquela que é descrita por Hume na seção 11 da parte 3 do $1^{\circ}$ livro do Tratado, quando introduz a noção de probabilidade de chances: o exemplo que ele ali analisa é o do lance de um dado, em que, frente às seis chances equivalentes de cada face do dado cair virada para cima, ou, dito de outra forma, frente a seis possibilidades entre as quais não encontramos nenhuma diferença, a imaginação recai em sua situação original de indiferença, sendo incapaz de fazer qualquer inferência:

Uma causa traça o caminho para nosso pensamento e, de certo modo, nos força a considerar objetos determinados em relações determinadas. Tudo que o acaso pode fazer é destruir tal determinação do pensamento, deixando a mente em seu estado original de indiferença, a que, na ausência de uma causa, ela retorna instantaneamente. ${ }^{16}$

Não importa que Hume negue explicitamente a realidade do acaso, e diga que este é apenas um nome que damos para causas que desconhecemos; aqui, no lance de dados, a situação se apresenta de tal maneira que a imagem de cada alternativa, embora semelhante às outras (pois cada lado tem exatamente a mesma chance de sair que os outros), é incompatível com elas (ou seja, não pode existir, não pode se tornar real, ao mesmo tempo que elas), sendo e permanecendo portanto absolutamente isolada, incapaz de se unir ou se fundir 
a elas para causar um peso e influência maiores sobre a imaginação. Frente a elas, portanto, a mente fica indiferente, sem inclinações. ${ }^{17}$

Ora, se essa situação restrita fosse ampliada até englobar toda a experiência, ou seja, se o mundo inteiro aparecesse a nós como um conjunto de alternativas absolutamente equipolentes, encontrar-nos-íamos em pé de igualdade com o Adão de Hume. O efeito geral seria, portanto, exatamente o do puro acaso, isto é, da pura ausência de causas, uma situação, podemos dizer, de quase atemporalidade, em que a experiência, ou nunca existiu, ou é anulada, e as determinações estabelecidas pelas causas e hábitos se desfazem. Não é à toa que, frente a um lance de dados, a mente não forma sequer um raciocínio por probabilidades de chances. Para explicar como formamos estes raciocínios, Hume precisará ainda considerar um dado que seja de algum modo assimétrico, o que permitirá a reintrodução de inclinações na mente. ${ }^{18}$

Nos Diálogos sobre a Religião Natural, uma situação parecida com essa que estou sugerindo aparece, na $2^{\mathrm{a}}$ parte, imaginada pelo personagem Filon: a ficção é agora, não mais de Adão, porém de um homem que se desfizesse por completo de sua memória e experiência, e tentasse então imaginar como seria o mundo.

Se um homem abstraísse de tudo que conhece ou viu, seria inteiramente incapaz de, apenas a partir de suas ideias, determinar a cena do universo, ou dar sua preferência a um estado ou situação de coisas ao invés de outro. Pois, como nada que ele concebe claramente poderia ser considerado impossível ou implicando uma contradição, todas as quimeras de sua fantasia estariam na mesma situação; e ele não poderia sequer dar uma boa razão pela qual adere a uma ideia ou sistema e rejeita outros que são igualmente possíveis. ${ }^{19}$

O ponto de Filon é mostrar que, sem hábitos e experiência passada, a atividade da imaginação seria por assim dizer selvagem, poderíamos fantasiar qualquer coisa, e não teríamos como fazer uma seleção entre as mais diversas possibilidades, e muito menos nos inclinar a crer em sua maior ou menor probabilidade. Antes de constatarmos o que de fato existe, tudo que concebemos pode se dar. E após vermos pela primeira vez o que se dá,

17 "Uma indiferença perfeita e total é essencial ao acaso [chance], e uma indiferença total jamais pode ser em si mesma superior ou inferior a outra. Essa verdade não é peculiar a meu sistema; ao contrário, é admitida por todo aquele que faz cálculos sobre chances". THN, 1.3.11.5; NN: 87; DD: 158.

18 Isso será feito por meio da suposição de um dado com quatro faces marcadas por um mesmo número de pontos e as outras duas marcadas por um número diferente. THN, 1.3.11.6; NN: 87; DD: 159.

19 DNR II, KS: 145; AM: 34 (aqui, em minha tradução). 
ainda assim tudo o mais que imaginamos pode acontecer. Nada nos diz que a natureza se manterá uniforme. ${ }^{20}$ Filon continua:

E após abrir os olhos e contemplar o mundo como ele realmente é, de início serlhe-ia impossível designar a causa de um único acontecimento, e muito menos da totalidade das coisas, ou do universo. Poderia dar asas à sua fantasia, e esta o levaria a uma infinidade de relatos e representações. Todos estes seriam possíveis; mas, sendo todos igualmente possíveis, ele jamais conseguiria por si mesmo dar uma explicação satisfatória de por que prefere um aos outros. Apenas a experiência pode lhe apontar a verdadeira causa de um fenômeno. ${ }^{21}$

Notemos que não se trata apenas, nessas ficções, do vislumbre de nosso "estado natural de ignorância quanto aos poderes e à influência de todos os objetos", como está dito na Investigação sobre o Entendimento, ${ }^{22}$ mas também de nosso estado natural de ignorância em relação aos valores desses objetos, e, ou de uma total indiferença e apatia, ou então de uma espécie de confusão afetiva frente aos mesmos. Veja-se este outro caso:

se uma pessoa adulta e de natureza igual à nossa fosse subitamente transportada para nosso mundo, ela ficaria bastante confusa com todos os objetos, e não descobriria facilmente que grau de amor ou ódio, orgulho ou humildade, ou qualquer outra paixão, deveria atribuir a eles. ${ }^{23}$

Se podemos sempre ao menos supor ideias e impressões (inclusive de prazer e dor) aparecendo pela primeira vez a um homem, assim como uma imaginação atuando, isto é, separando e associando ideias, de maneira independente do hábito e da causação, é impossível fazer o mesmo tipo de suposição em relação às paixões. É possível, sim, haver objetos que não nos dão nem prazer nem desprazer, e que nos são indiferentes neste sentido, a saber, não interessam nem despertam nossas paixões. ${ }^{24}$ Mas como sentir medo de algo se não temos ideia de seus efeitos? Como desejar um objeto se não sabemos que nos proporcionará prazer? Em outras palavras, como haver paixões onde não há experiência em sentido forte, e onde não realizamos inferências de causa e efeito? ${ }^{25}$

20 Ver também EHU IV.I.25, N/SB: 29; AM: 57-58.

21 DNR, ibid. O objetivo específico de Hume (Fílon) neste trecho dos Diálogos é argumentar que a regularidade e a harmonia que caracterizariam nosso mundo não nos permitem concluir com certeza uma inteligência ou desígnio supremo como sua causa, visto que esta não faz parte de nossa experiência.

22 EHU IV.II.32; N/SB: 37; AM: 67.

23 THN 2.1.6.9; NN: 192; DD: 328.

24 Talvez devêssemos neste caso falar antes em "desinteresse" do que em "indiferença".

25 Além disso, a contingência e a incerteza da experiência são ainda mais visíveis no caso das paixões do que no de nossos raciocínios sobre questões de fato, uma vez que as paixões são muito instáveis, e 
Em suma, não seríamos o que somos, se não estivéssemos já sempre no meio: no meio da experiência, de sistemas de valores, da sociedade, da política, dos outros homens. ${ }^{26}$

Podemos arriscar extrair uma ou duas conclusões de tudo que foi dito. Ao retratar situações em que a experiência perde sua qualidade de "princípio da natureza humana" - porque, embora ela própria se mantenha a mesma, o que se supõe é um ser estranho à nossa natureza e ao nosso mundo tendo seu primeiro contato com ela, ou então um homem como nós, porém despido de todas a suas memórias, e portanto, em certo sentido, despido também de sua natureza humana -, todas essas ficções inventadas por Hume parecem por um lado querer apresentar o contrário daquilo que retratam. Pois nós sobretudo não somos esses seres estranhos. Nós não somos eles, nem que quiséssemos. Mesmo que fôssemos para um outro mundo ou simplesmente para uma ilha deserta, não poderíamos deixar de levar sempre conosco nossos semelhantes, a lembrança da regularidade de fato da natureza, nossa própria sociedade ou civilização. Assim, por exemplo, utilizando imagens que reconheceríamos talvez em Robinson Crusoe, de Defoe, ${ }^{27}$ Hume mostra como, ao contrário do que ocorre com o "extraterrestre" que subitamente viesse a nosso mundo, nós, mesmo em uma situação solitária, e a partir de um objeto isolado, seríamos sempre capazes de reconstruir toda a nossa realidade: "Se você visse à beira

suscetíveis de variações por princípios e circunstâncias frequentemente desprezíveis. Daí a necessidade de regras gerais, sem as quais a atribuição de valores diferenciados aos objetos tornar-se-ia uma arte por demais refinada para operar de maneira tão universal sobre o homem comum. Mesmo as paixões diretas, que se originam imediatamente do sentimento de prazer ou de dor, não se reduzem simplesmente a estes. Por isso, apenas o costume e a prática, ao criarem máximas gerais, permitem que atribuamos aos objetos e ações um valor preciso. "As paixões frequentemente variam por causa de princípios insignificantes; e estes nem sempre atuam com uma regularidade perfeita, sobretudo na primeira tentativa. Mas o costume e a prática tornam claros todos esses princípios, determinando o valor correto de cada coisa, o que certamente contribui para a fácil produção dessas paixões, e para nos guiar, mediante máximas gerais estabelecidas, acerca das proporções que devemos guardar ao preferir um objeto a outro". Ibid.

26 Sobre a sociedade, mais uma ficção: "Se uma geração de homens saísse de cena de uma só vez e uma outra a sucedesse, como ocorre com os bichos-da-seda e as borboletas, a nova raça, se tivesse bom senso suficiente para escolher seu governo, o que certamente nunca acontece com os homens, poderia voluntariamente, e por um consenso geral, estabelecer sua própria forma de política civil, sem qualquer preocupação com as leis ou precedentes que prevaleciam entre seus ancestrais. Mas como a sociedade humana está em perpétuo fluxo, com um homem a toda hora deixando o mundo e outro entrando, é necessário que, para preservar a estabilidade no governo, a nova geração se conforme com a constituição estabelecida, e siga de perto os passos que seus pais, seguindo os dos seus, haviam-lhes demarcado." Essays, "Of the original contract", pp.476-77.

27 É provável que Hume conhecesse Robinson Crusoe, publicado em 1719. Cf. N.K. Smith, na introdução à sua edição dos Dialogues concerning Natural Religion, pp. 54-55. 
do mar a marca de um pé humano, concluiria que um homem havia passado por ali, e que também havia deixado a marca do outro pé, apenas apagada pelo deslizar da areia ou pela maré". ${ }^{28}$ Ou então: "Um homem que encontrasse um relógio ou outra máquina qualquer em uma ilha deserta concluiria que outros homens já haviam estado naquela ilha". ${ }^{29}$

Ainda que estas fossem as únicas marcas da presença humana naquelas paisagens, a ilha ou a praia deserta não passam de recortes na totalidade da experiência, que aponta ao homem que todos os objetos semelhantes por ele já vistos sempre tiveram a mesma causa, a saber, a arte, a inteligência e o desígnio humanos. Ora, efeitos semelhantes supõem causas semelhantes e, portanto, a inferência do homem solitário não poderia ser diferente. Não há mundo de um homem só, não há "mundo sem outrem". ${ }^{30}$

Por outro lado, entretanto, por vezes somos tomados por uma dúvida profunda, por uma forte, ainda que surda, suspeita. Percebemos que nunca poderíamos nos livrar completamente da incerteza e da singularidade da experiência. Tudo que é concebível é possível, e por isso desconfiamos de que, a qualquer momento, poderíamos ser surpreendidos por um mundo que não esperávamos, por um mundo completamente alheio a este com que estamos tão familiarizados, muito mais alheio que uma ilha deserta. Frente à imagem do Adão desamparado, ou do homem que caiu na Terra e não sabe o que pensar ou sentir, é como se subitamente indagássemos: não há sempre o perigo de estes outros serem já nós mesmos? Não somos todos ETs em potencial de nosso próprio mundo? ${ }^{31}$ Cito as palavras de Gilles Deleuze, num pequeno artigo sobre Hume:

... Hume tem uma posição muito particular. Seu empirismo é, antecipadamente, uma espécie de universo de ficção científica. Como na ficção científica, tem-se a impressão de um mundo fictício, estranho, estrangeiro, visto por outras criaturas; mas

28 EHU XI.111; N/SB: 143; AM: 195 (tradução um pouco modificada)

29 EHU IV.I.22, N/SB: 26; AM: 55 (tradução um pouco modificada).

30 Tomo emprestada essa expressão de um dos apêndices de Gilles Deleuze ao seu livro Logique du sens, "Michel Tournier et le monde sans autrui", reflexão acerca do livro de Tournier, Vendredi ou les Limbes du Pacifique. É curioso que, num outro sentido, a filosofia de Hume suponha justamente um "mundo sem outrem". Sua análise da ficção da existência distinta e independente dos corpos externos deixa bem claro que, diferentemente do que ocorre com George Berkeley, para quem Deus é o grande "outrem" que garante a existência e a regularidade dos objetos que, não eu, mas outros espíritos finitos, podem estar observando, em Hume, como não há uma substância espiritual e o recurso a Deus seria de todo modo ilegítimo, essa garantia não existe em nenhuma parte. Tudo se limita às nossas percepções, e por isso o mundo exterior só será posto através de uma ficção. Sobre isso, cf. também o que Hume diz em carta: "Nenhum homem pode ter qualquer outra experiência que não seja a sua própria" (Greig, 1932).

31 Talvez seja em parte essa sensação de estranhamento invertido que Hume descreve tão soberbarmente no final do livro I do Tratado, como pus na epígrafe ao presente artigo. THU: 1.4.7.2; NN: 172; DD: 296. 
também o pressentimento de que esse mundo já é o nosso e essas outras criaturas, nós próprios. ${ }^{32}$

É como se, nesses exemplos, nós nos descobríssemos sob a "atração" de duas forças, entre as quais na verdade parece se desenrolar toda a filosofia de Hume: uma força que nos puxa em direção à regularidade e uniformidade das leis da natureza e da natureza humana, afastando-nos permanentemente da singularidade, da pura diferença entre percepções atômicas ${ }^{33}$ e da indiferença original da imaginação; e uma outra, que apenas entrevemos, mas que se mantém como uma ameaça constante por trás de todas as associações, inferências, crenças e mecanismos de paixões — o reino da pura singularidade, a recaída na indiferença, a ruína da natureza humana ${ }^{34}$ Creio não ser exagerado dizer que, em poucos momentos da nossa história, sentimos tão de perto o perigo, ou talvez precisamente a perversa atração, dessa segunda força.

\section{Referências bibliográficas}

DANOWSKI, D. Natureza Acaso: a contingência na filosofia de David Hume. Rio de Janeiro: PUC-Rio, 1991.

"Deleuze avec Hume". In: E. Alliez (org.), Gilles Deleuze: une vie philosophique. Le Plessis-Robinson: Institut Synthélabo/Les Empêcheurs de Penser en Rond, 1998: 191-206.

. "Leibniz e Hume sobre a indiferença". Kriterion XLIV n ${ }^{\circ} 108$, jul a dez 2003: 209-223.

DELEUZE, G. Logique du Sens. Paris: Minuit, 1969.

. "Hume". In Châtelet, F. (org.). História da Filosofia: idéias, doutrinas, vol. 4: O Iluminismo (o século XVIII). Rio de Janeiro: Zahar Editores, 1973.

GREIG, J. Y. T. (ed.). The Letters of David Hume. Oxford: Clarendon Press, 1932.

HACHE, E. \& Latour, B. "Morale ou moralisme? Un exercice de sensibilisation". Raisons Politiques, 34 (2): 143-165, 2009.

HUME, D. A Treatise of Human Nature (eds. David Fate Norton \& Mary J. Norton). Oxford: Clarendon Press, 2007.

. Tratado da Natureza Humana (trad. D. Danowski). São Paulo: Edunesp, 2001 . An Abstract of ... A Treatise of Human Nature. In Hume 2007: 403-417. . Sinopse [do] ... Tratado da Natureza Humana. In Hume 2001: 679-699. 
Dialogues concerning Natural Religion (ed. Norman Kemp Smith). Nova York: Macmillan, 1989.

- Diálogos sobre a Religião Natural (trad. J. O. de Almeida Marques). São Paulo: Martins Fontes, 1992. Fund, 1985.

. An Enquiry concerning Human Understanding. In Enquiries concerning Human Understanding and concerning the Principles of Morals (ed. L.A. SelbyBigge). Oxford: Clarendon Press, 1986.

—. Investigação sobre o Entendimento Humano. In Investigações sobre o Entendimento Humano e sobre os Princípios da Moral. (trad. J. O. de Almeida Marques). São Paulo: Editora Unesp, 2004.

- The Natural History of Religion (ed. H.E. Root). Stanford: Stanford University Press, 1981.

KEMP SMITH, N. "Introduction". In Hume, D. Dialogues concerning Natural Religion. Nova York: Macmillan, 1989.

MALHERBE, M. La Philosophie Empiriste de David Hume. Paris: J. Vrin, 1984. 